\title{
LEVANTAMENTO DO ESTADO DEGRADAÇÃO DAS EDIFICCAÇÕES INVENTARIAS NA CIDADE DE PELOTAS/RS: ZONA DE PRESERVAÇÃO DO PATRIMÔNIO CULTURAL, SÍTIO DO $1^{\circ}$ LOTEAMENTO
}

\author{
COSTA, Vitória Silveira da \\ Arquiteta e Urbanista, Mestranda. \\ Pós-Graduação em Arquitetura e Urbanismo, Universidade Federal de Pelotas \\ Rio Grande do Sul; Brasil \\ vitoriascosta@yahoo.com.br

\section{TORRES, Ariela da Silva} \\ Engenheira Civil, Professora Doutora. \\ Pós-Graduação em Arquitetura e Urbanismo, Universidade Federal de Pelotas \\ Rio Grande do Sul; Brasil \\ arielatorres@gmail.com
}

\section{RESUMO}

A preservação do patrimônio cultural vem ao encontro da valorização das memórias culturais. Segundo o Instituto do Patrimônio Histórico e Artístico Nacional (IPHAN), 88 conjuntos urbanos estão sob proteção do instituto, sendo treze cidades localizadas na região Sul do Brasil. A cidade de Pelotas situada no Rio Grande do Sul têm-se dois núcleos importantes para formação histórico-cultural da cidade: um às margens do Arroio Pelotas e outra no centro histórico da cidade. Ao longo da vida dos edifícios devem existir preocupações de manutenção, sendo as fachadas, um dos componentes que demanda maiores cuidados, uma vez que se encontram mais expostas aos mecanismos de degradação. No caso das edificações que compõem o patrimônio histórico as manifestações patológicas algumas vezes são causadas por uma série de fatores específicos, originadas pelas singularidades encontradas neste tipo de edificação. Este trabalho propõe-se a realizar o levantamento do estado de degradação das fachadas de edificações históricas na cidade de Pelotas/RS por meio do estudo de caso e aplicação do Método de Mensuração da Degradação (MMD). A pesquisa avaliou o estado de degradação de duas fachadas de edificações inventariadas da cidade de Pelotas, localizadas na Zona de Preservação do Patrimônio Cultural (ZPPC) no sítio do $1^{\circ}$ loteamento. Como resultados a partir da aplicação do MMD conclui-se que o fator de dano total das fachadas é de $12,17 \%$ e $118,40 \%$ sendo em ambas as edificações os danos mais recorrentes machas de umidade, mofo e bolor; descolamento de pintura e fissuras.

Palavras-chave: manifestações patológicas, conservação, fachadas, patrimônio histórico.

\section{ABSTRACT}

The preservation of cultural heritage meets the appreciation of cultural memories. According to the Institute of National Historical and Artistic Heritage (IPHAN), 88 urban areas are under the protection of the institute, thirteen cities located in the southern region of Brazil. The city of Pelotas located in Rio Grande do Sul has two important nuclei for historical and cultural formation of the city: one on the banks of Arroio Pelotas and another in the historical center of the city. Throughout the life of buildings there should be maintenance concerns, with façades being one of the components that requires more care, as they are more exposed to degradation mechanisms. In the case of the buildings that make up the historical heritage, pathological manifestations are sometimes caused by a series of specific factors, originated by the singularities found in this type of building. This paper proposes to survey the state of degradation of the façades of historic buildings in the city of Pelotas / RS through the case study and application of the Degradation Measurement Method (MMD). The research evaluated the state of degradation of two façades of inventoried buildings in the city of Pelotas, located in the Cultural Heritage Preservation Zone (ZPPC) on the site of the 1st subdivision. As a result of the application of the MMD it is concluded that the total damage factor of the facades is $12.17 \%$ and $115.18 \%$ being in both buildings the most recurrent damages of moisture, mold and mold; paint detachment and cracks.

Keywords: pathological manifestations, conservation, facades, historical heritage.

\section{INTRODUÇÃO}

O Brasil é o país pioneiro na América Latina em relação à formulação de uma legislação específica para a preservação do patrimônio cultural. Segundo o Instituto do Patrimônio Histórico e Artístico Nacional (IPHAN), 88 conjuntos urbanos protegidos estão sob proteção do instituto. Dentre as cidades acauteladas pelo instituto, treze cidades estão 
localizadas na região Sul do país - Lapa (PR), Paranaguá (PR), Jaguarão (RS), Pelotas (RS), Porto Alegre (RS) e Laguna (SC). Apesar do IPHAN atuar e investir recursos na forma de obras de qualificação e por meio de parcerias com outras instituições municipais e estaduais, menos de $10 \%$ das áreas tombadas em nível nacional dispõe de normas eficientes capazes de nortearem as intervenções nos conjuntos históricos (IPHAN, 2010; IPHAN, 2019).

A preservação do patrimônio cultural da cidade de Pelotas é de extrema importância para a preservação da história da construção e da identidade cultural da cidade (ALMEIDA e BASTOS, 2006). A primeira manifestação oficial pelo Serviço do Patrimônio Histórico e Artístico Nacional (SPHAN) em relação à preservação do patrimônio cultural de Pelotas ocorreu apenas em 1955, com o tombamento federal do Obelisco Republicano no bairro do Areal (SCHLEE, 2008). Contudo, sem uma adequada política de preservação, o patrimônio pelotense continuou dependendo da iniciativa e mobilização da comunidade do munícipio. Posteriormente, o II Plano Diretor da cidade inseriu os primeiros conceitos de preservação em nível municipal (ALMEIDA E BASTOS, 2006; RIBEIRO, 2013).

Na cidade de Pelotas, no ano de 2002, houve uma importante revisão no Código Tributário do município que previu a possibilidade de isenção de Imposto Predial e Territorial Urbano (IPTU) aos imóveis integrantes do inventário (ALMEIDA e BASTOS, 2006). Em 2008 foi instituído o III Plano Diretor da cidade que delimita as Áreas de Especial Interesse do Ambiente Cultural (AEIAC). Outra importante ferramenta de preservação na cidade de Pelotas foi a criação de quatro Zonas de preservação do Patrimônio Cultural (ZPPC) (RODRIGHIERO e OLIVEIRA, 2018). As zonas foram delimitadas seguindo o processo de formação e desenvolvimento urbano de Pelotas, estando divididos conforme a Figura $1 \mathrm{em}$ : o Sítio do $1^{\circ}$ loteamento, Sítio do $2^{\circ}$ loteamento, Sítio do Porto e o Sítio da Caieira (RIBEIRO, 2013). Os imóveis inventariados são classificados de acordo com níveis de preservação. Tais níveis são um instrumento de gestão e conservação dos prédios históricos que tem por objetivo estabelecer diferentes instâncias de proteção de acordo com as características remanescentes de cada bem.

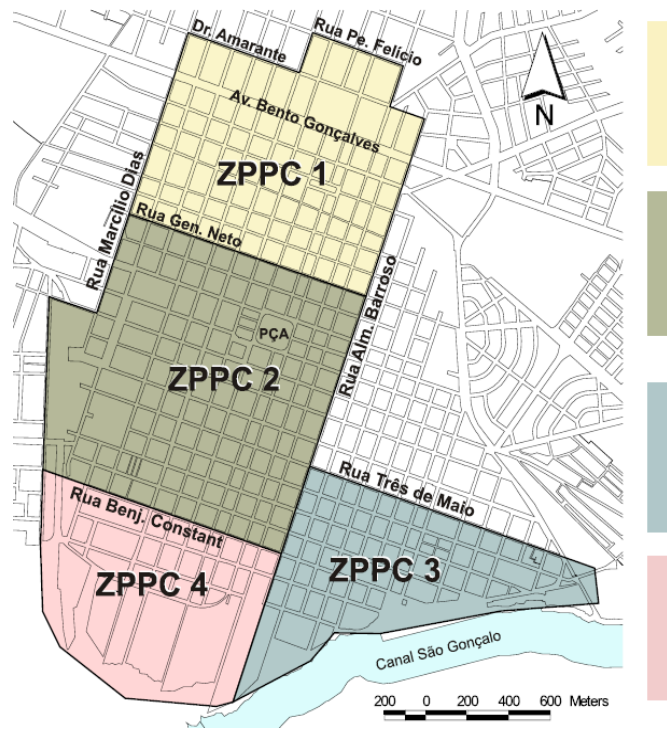

ZPPC 1-Sítio do $1^{\circ}$ Loteamento:

Corresponde ao primeiro núcleo urbano de Pelotas, configurado ao redor da antiga Igreja da Freguesia, atual Catedral São Francisco de Paula.

ZPPC 2 - Sítio do $2^{\circ}$ Loteamento:

Região do entorno da Pça Cel. Pedro Osório que desde o século XIX caracteriza-se como o centro da cidade. Representa o poder e a riqueza da época das charqueadas, através de seus prédios de arquitetura eclética.

\section{ZPPC 3 - Sítio do Porto:}

Zona localizada à beira do Canal São Gonçalo onde eram desenvolvidas as atividades portuárias da cidade, importantes para o desenvolvimento da indústria do charque e dos produtos manufaturados.

\section{ZPPC 4 - Sítio da Caieira:}

Região onde eram realizadas atividades de fabricação da cal, nas imediações da linha férrea, junto à Rua Conde de Porto Alegre.

Figura 1: Localização das Zonas de Preservação do Patrimônio Cultural de Pelotas. Fonte: Manual do Usuário de Imóveis Inventariados, 2008.

O mapa da AEIAC é também utilizado na definição e na descrição dos imóveis inventariados. A Lei municipal $n^{\circ}$ 4.568/2000, juntamente com o decreto $\mathrm{n}^{\circ}$ 4.490/2003, lista a relação de imóveis inventariados, especificando o número de matrícula do imóvel, seu endereço e zona de proteção à qual pertence. Os imóveis inventariados são classificados de acordo com níveis de preservação, sendo estes descritos nas fichas de cada imóvel, e são consequência da demarcação de uma série de características arquitetônicas (descritas no III Plano Diretor) convertidas em um fator numérico, que determina um dos quatro níveis de preservação. Os imóveis inventariados são classificados de acordo com níveis de preservação, estando, no III Plano Diretor, descritas as características dos quatro níveis de preservação. Tais níveis são um instrumento de gestão e conservação dos prédios históricos que tem por objetivo estabelecer diferentes instâncias de proteção de acordo com as características remanescentes de cada bem.

Levando-se em consideração todos os aspectos apontados sobre a evolução da cidade de Pelotas/RS sobre os quesitos de preservação e da importância da salvaguarda do patrimônio, faz-se necessário a investigação acerca das 
manifestações patológicas e do estado de degradação das fachadas. Portanto, devem existir preocupações de manutenção e reabilitação, uma vez que as fachadas são os componentes que demandam maiores cuidados em vista da exposição e das ações dos agentes de degradação. Este trabalho propõe-se em avaliar o estado de degradação das fachadas de edificações inventariadas da cidade de Pelotas/RS, localizadas dentro da Zona de Preservação do Patrimônio Cultural (ZPPC) na área do sítio do $1^{\circ}$ loteamento - optou-se por trabalhar com imóveis inseridos dentro dos limites da ZPPC em vista de sua importância para formação da cidade - por meio do estudo de caso e aplicação do Método de Mensuração da Degradação (MMD).

\section{METODOLOGIA}

Essa seção descreve as metodologias utilizadas como base para o levantamento das manifestações patológicas e análise do estado de degradação. Sendo elaborado o mapa de danos para representação gráfica das anomalias do Método de Mensuração de Degradação de Danos (MMD) para a quantificação e análise de conservação das fachadas.

\subsection{Objetos de Estudo}

Para a realização do presente do estudo foram escolhidos dois imóveis localizados na região central de Pelotas, pertencentes à Zona de Patrimônio de Proteção Cultura (ZPPC) situados no Sítio do $1^{\circ}$ loteamento, segundo classificação do III Plano Diretor de Pelotas. As fachadas possuem orientação solar Sudeste diferindo-se no uso de cada edificação. A edificação de $n^{\circ} 817$ é atualmente utilizado para o funcionamento de uma clínica odontológica conforme a Figura 2. Já o imóvel de n 1021 apresentado na Figura 3 encontra-se em situação de desuso.

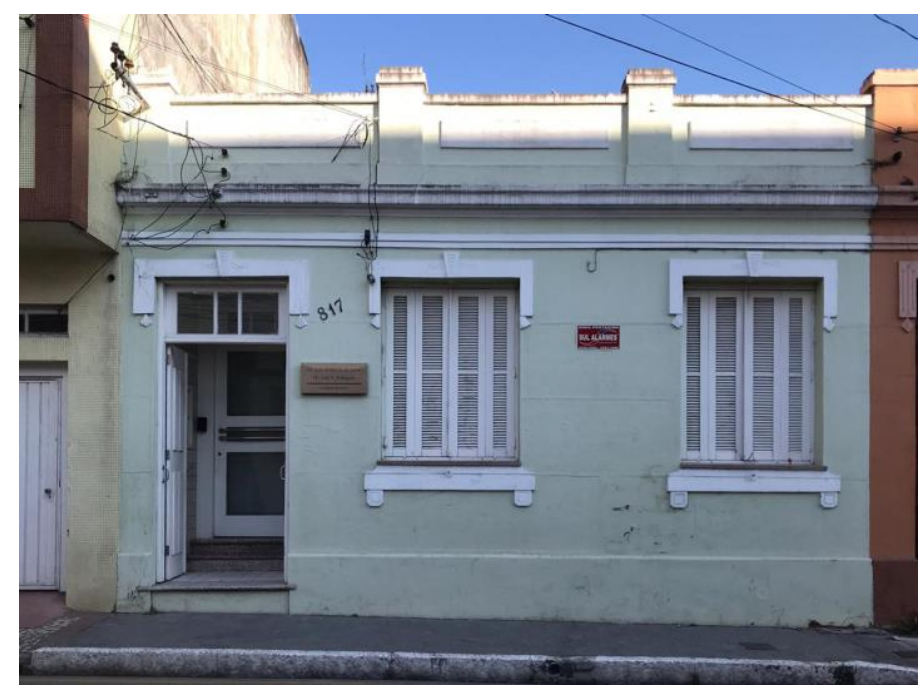

Figura 2: Fachada do imóvel nº 817.

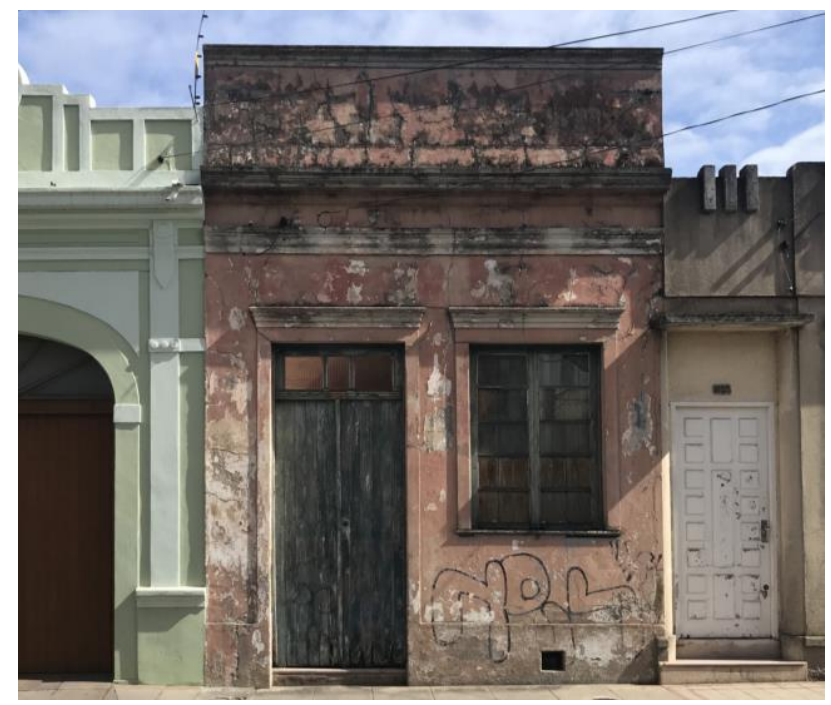


Figura 3: Fachada do imóvel nº 1021.

\subsection{Mapa de Danos}

Mapas de danos são documentos gráficos que sintetizam informações a respeito do estado de conservação geral de um edifício, por meio de símbolos gráficos com os quais se representam as diversas categorias e níveis de degradação identificados (TIRELLO e CORREA, 2012). Sendo assim, o desenvolvimento do mapa de danos consiste em uma representação gráfico-fotográfica, rigorosa e minuciosa de todas as manifestações patológicas da edificação, ao qual sintetiza o resultado das investigações sobre as alterações da edificação (TINOCO, 2009). Apesar de ser uma importante etapa do projeto de restauro, o mapa de danos não possui ainda nenhum tipo de normatização para sua representação gráfica. Desta maneira, suscita em uma grande diversidade de representações que, apesar de normalmente estarem tecnicamente corretas, geram problemas na análise dos projetos por parte das instituições de preservação do patrimônio, de orçamentistas e, principalmente, no canteiro de obras (HAUTEQUESTT FILHO e ACHIAMÉ, 2018).

Segundo Tirello e Correa (2012), constata-se uma escassa literatura nacional disponível sobre a temática, acarretando hiatos informativos a respeito dos procedimentos técnicos e das questões conceituais-operativas que envolvem a elaboração de um Mapa de Danos. Sendo essa problemática observável no documento redigido pelo IPHAN "Manual de elaboração de projetos de preservação do patrimônio cultural". O "Manual de elaboração de projetos de preservação do patrimônio cultural" do programa MONUMENTA do IPHAN, é um texto que se propõe como um roteiro oficial para elaboração de projetos de restauro a serem submetidos à aprovação na área do patrimônio histórico. Sendo, o mapa de danos associado à conservação do patrimônio edificado, o documento do IPHAN define com exiguidade e falta de clareza tal procedimento.

A Associação Brasileira de Normas Técnicas (ABNT), responsável pela elaboração e edição de normativas no Brasil, não conta com normas aplicáveis ao estudo diagnóstico do patrimônio histórico arquitetônico. As normas encontradas no órgão brasileiro versam apenas sobre a manutenção de edificações com materiais contemporâneas (NBR 5674: Manutenção de edificações - Requisitos para o sistema de gestão de manutenção) não privilegiando o patrimônio histórico.

O estudo realizado por Ioshimoto (1988) em conjuntos habitacionais de casas térreas construídas de alvenaria de tijolos, propõe uma classificação para as manifestações patológicas a partir das causas, com a subdivisão proposta pelo autor em umidade, fissuras e trincas e descolamento do revestimento. Diversos estudos atuais, como Al Alam (2016), Rodrigues (2016), Silva (2016), Zanoni (2015) e Pereira (2012) ainda utilizaram esta classificação.

As manifestações patológicas podem ser classificadas de diversas formas. Para descrição dos danos em revestimento argamassado de fachadas se utilizará a classificação a partir dos danos proposta por Ioshimoto (1988). Em vista do trabalho de Terra (2001), também será abordado o tópico de sujidade, uma que vez os resultados encontrados pelo autor evidenciam ser este o tipo de lesão mais frequente na cidade de Pelotas/RS. Além disso, a autora Vieira (2005) apresenta dados sob a influência dos detalhes arquitetônicos no estado de conservação das fachadas do Centro Histórico de Porto Alegre, tendo como resultado a presença de manchamentos devido a deposição de partículas de sujidade sobre os paramentos das fachadas nos casos estudados.

Desta maneira, para elaboração do mapa de danos fez-se necessário a criação de uma legenda em cores para representar as anomalias presentas nas edificações conforme pode ser visto na Figura 04.

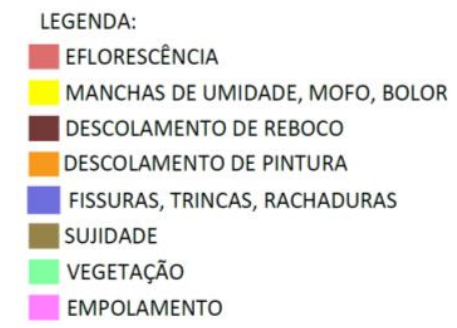

Figura 4: Legenda das manifestações patológicas.

Com o propósito de possibilitar a ampliação das fotografias para melhor análise, a câmera utilizada para o levantamento permitiu fotografias em alta resolução e, assim, uma boa visualização das imagens obtidas em levantamento. Para exequibilidade do mapa de danos sobre as fotografias retiradas em levantamento, realizou o ajuste de perspectiva com o auxílio do software Photoshop, tal medida serviu para corrigir distorções ocorridas por conta do ângulo em que o 
imóvel foi fotografado e para que a área do mesmo fosse fidedigna, desta maneira possibilitando as identificações gráficas das manifestações patológicas em desenho 2D no software AUTOCAD.

\subsection{Método de Mensuração de Degradação (MMD)}

O Método de Mensuração da Degradação (MMD) vem sendo desenvolvido e aplicado pelo Laboratório de Ensaio de Materiais da Universidade de Brasília - LEM/UnB em diversos estudos de caso, com destaque para o estudo de Silva (2014), que aperfeiçoou a aplicação da metodologia. No presente trabalho, o MMD foi aplicado em etapas: ajuste do mapa de danos e sobreposição da malha; quantificação das áreas danificadas; cálculo do Fator de Dano Total (FD) da fachada; divisão da fachada em regiões; cálculo do Fator de Dano das Regiões (FDR); cálculo do Coeficiente de Correção das Regiões (CCr); cálculo do Fator de Dano das Regiões Corrigido (FDRC).

Inicialmente, foi realizado o ajuste no mapa de danos utilizando a classificação das anomalias de acordo com Santos (2018) o qual retira da classificação a presença de sujidade e vegetação. Ainda, foi sobreposta a malha de $15 \mathrm{~cm} \times 15 \mathrm{~cm}$ com ponto de origem na extremidade inferior (Figura 5), reduzindo a área da malha, com vistas a proporcionar um resultado mais detalhado no levantamento uma vez que os estudos foram realizados em edificações de múltiplos pavimentos.

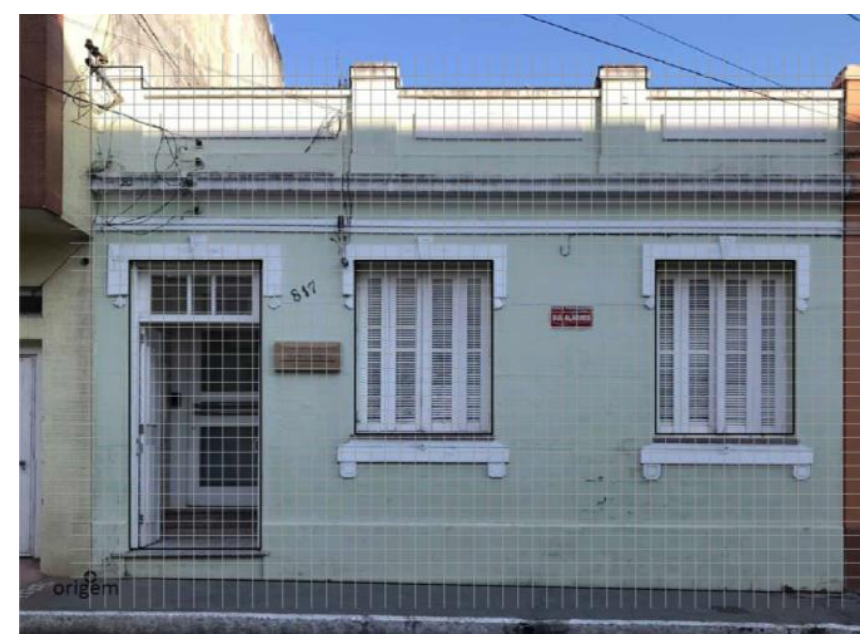

Figura 5: Fachada n 817 com a sobreposição de malha para análise.

Ainda nesta etapa realizou-se o novo mapeamento dos danos os quais pressupõe a presença de determinado dano na malha deve-se considerar a área como afetada por determinada manifestação patológica, Figura 6.

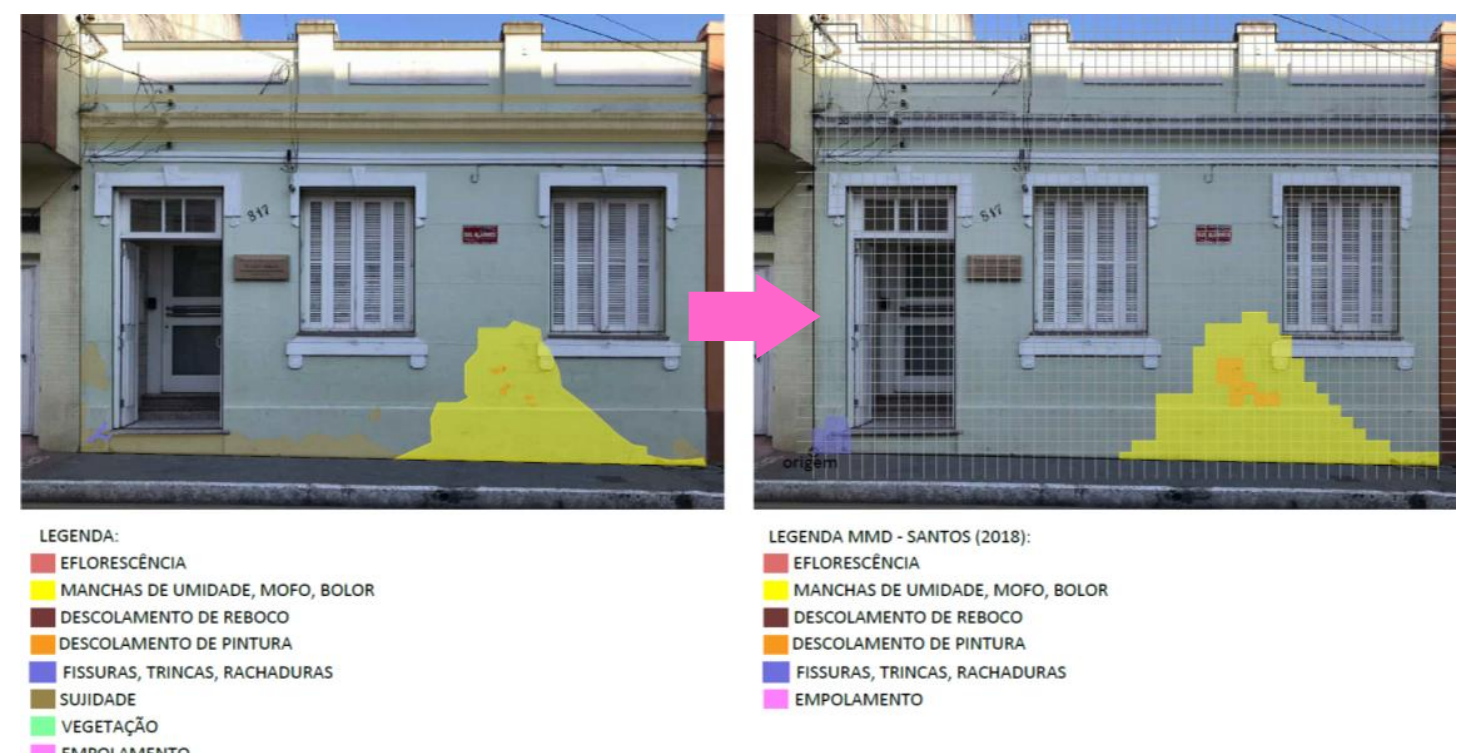

Figura 6: Fachada no 817 - Ajuste do mapa de danos para o MMD. 
$\mathrm{Na}$ segunda etapa tem-se a quantificação das áreas danificadas, a partir da contagem simples de unidades de malha e multiplicação pela sua área foi identificado o valor de sua área total e da área danificada por cada anomalia. Na etapa do cálculo de Fator de Dano Total (FD) da fachada realiza-se o somatório das áreas danificadas da anomalia dividida pela área total da fachada, nesta etapa obtém-se os valores das manifestações patológicas mais representativas nas fachadas. Para o cálculo do Fator de Dano das Regiões (FDR) faz-se necessário a divisão das fachadas em regiões. Conforme a Figura 7, a fachada foi dividida em regiões, conforme indicado por Silva (2014): Sacada (SC), Aberturas (AB), Cantos e Extremidades (CE), Transição entre pavimentos (TP), Topo (TO) e Paredes Contínuas (PC).

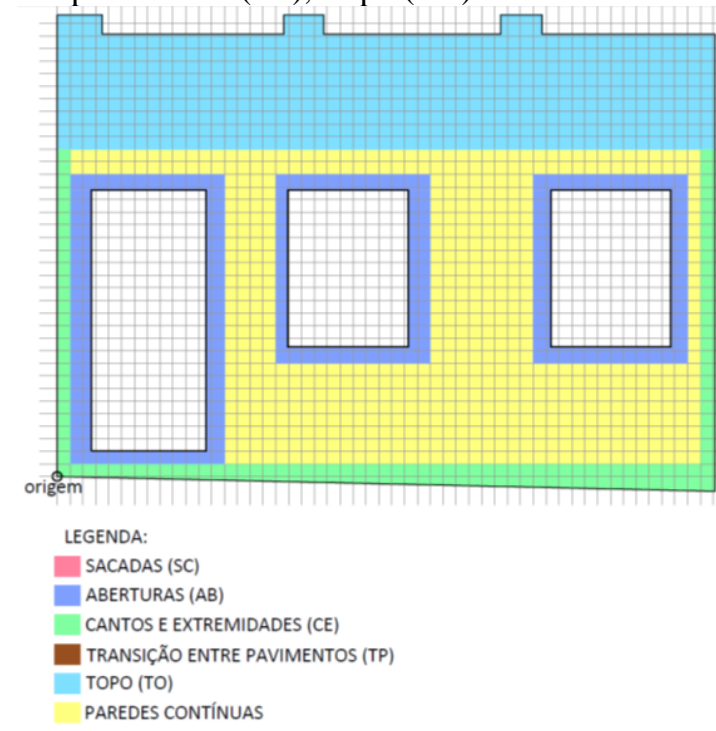

Figura 7: Fachada no 817 - Divisão da fachada em regiões.

Após a divisão da fachada em regiões é possível calcular o Fator de Dano das Regiões (FDR), esse índice, leva em consideração a área com presença de anomalias em cada região da fachada (Figura 8), considera-se aqui todas as manifestações contidas nesse espaço. Seu resultado apresenta distorção da realidade ao ser influenciado diretamente pelo tamanho da área da região, por isso, deve ser ajustado e proporcionalizado.

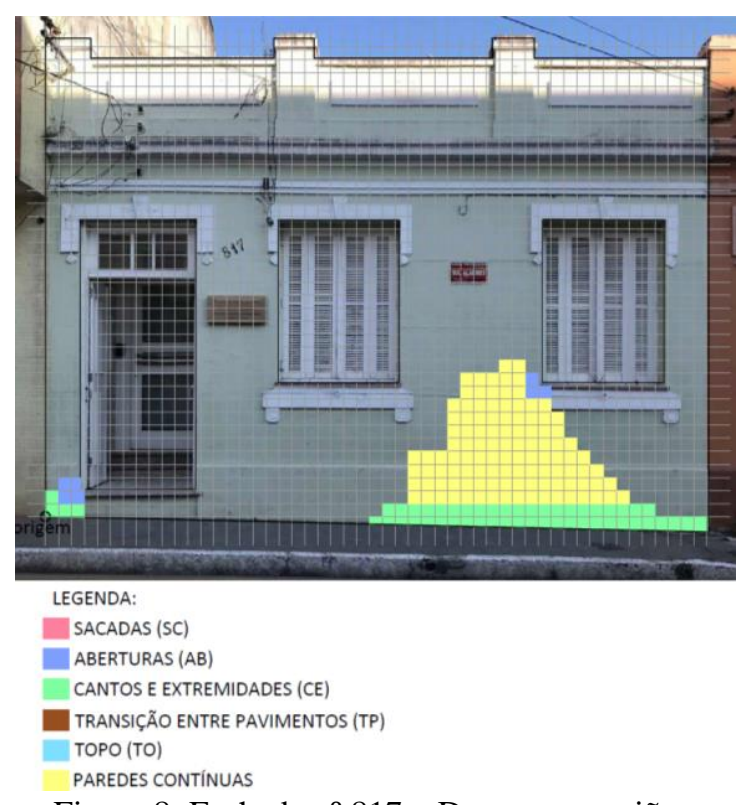

Figura 8: Fachada $n^{\circ} 817$ - Danos nas regiões.

Algumas regiões da fachada abrangem áreas muito maiores do que as outras, o que distorceria o resultado final da análise de incidência das anomalias, ou seja, regiões com maiores áreas apresentariam um maior índice de degradação quando comparada a regiões com menores áreas. Para corrigir essa desproporcionalidade, utiliza-se o Coeficiente de Correção das regiões (CCr). Para finalizar, após o cálculo do $\mathrm{CCr}$, passa-se a última etapa no cálculo do MMD, que é o 
cálculo do Fator de Dano das Regiões Corrigido (FDRC). Como o próprio nome sugere, o FDRC é obtido pela multiplicação do FDR pelo seu respectivo CCr. Com temos a representação mais aproximada da real recorrência dos danos presentes nas regiões da fachada.

\section{RESULTADOS E DISCUSSÕES}

Nessa seção serão apresentados os resultados oriundos do mapa de danos e da aplicação do MMD.

\subsection{Mapa de Danos}

Como resultado da investigação de campo, a elaboração do Mapa de Danos possibilitou a visualização clara e objetiva do cenário existente das manifestações patológicas identificadas nas fachadas, proporcionando a organização de um instrumento base para aplicação de métodos para avaliação do estado de conservação. Como manifestações patológicas mais representativas em ambas fachadas se destaca a presença de manchas de umidade, mofo e bolor conforme pode ser visualizado nas Figuras 9 e 10.

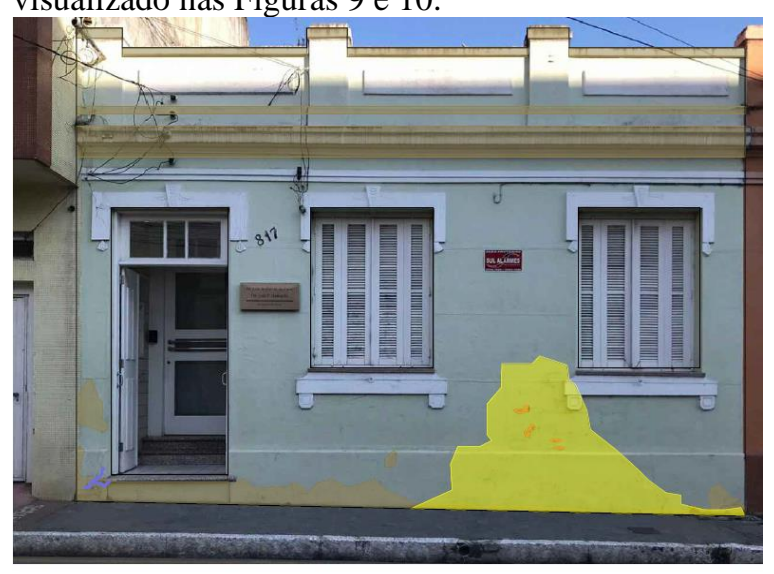

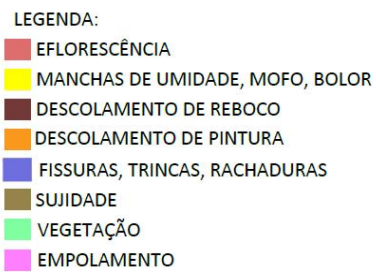

Figura 9: Mapa de danos - Fachada $n^{\circ} 817$.

\subsection{Método de Mensuração de Degradação (MMD)}

O mapa de danos adaptado aos critérios do método MMD com sobreposição de malha estão representados nas Figuras 11 e 12 e seus resultados estão apresentados na Tabela 1 juntamente com o Fator de Dano Total (FD) de cada fachada.

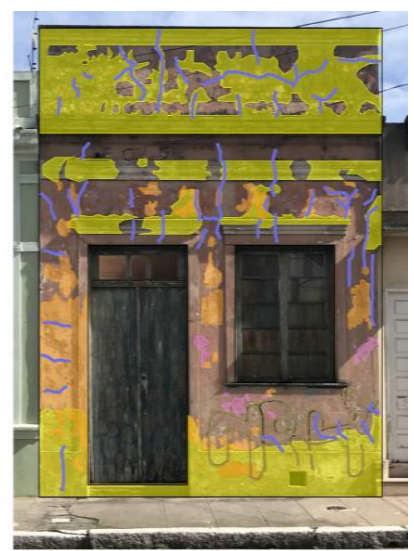

LEGENDA:

EFLORESCÊNCIA

MANCHAS DE UMIDADE, MOFO, BOLOR

descolamento de ReBOco

DESCOLAMENTO DE PINTURA

FISSURAS, TRINCAS, RACHADURAS

SUJIDADE

VEgetAÇÃo

empolamento

Figura 10: Mapa de danos - Fachada n 1021. 


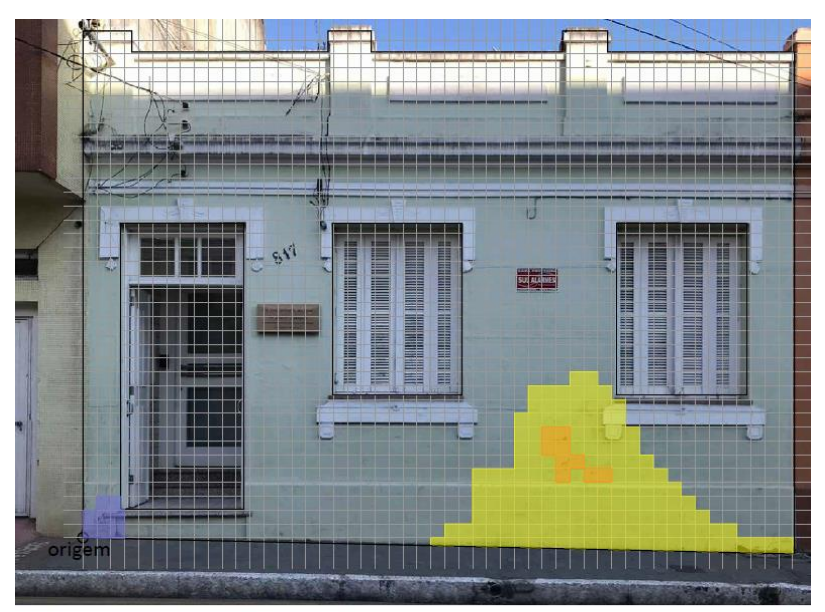

LEGENDA MMD - SANTOS (2018):

EFLORESCÊNCIA

MANCHAS DE UMIDADE, MOFO, BOLOR

DESCOLAMENTO DE REBOCO

DESCOLAMENTO DE PINTURA

FISSURAS, TRINCAS, RACHADURAS

EMPOLAMENTO

Figura 11: Mapa de danos MMD - Fachada no 817.

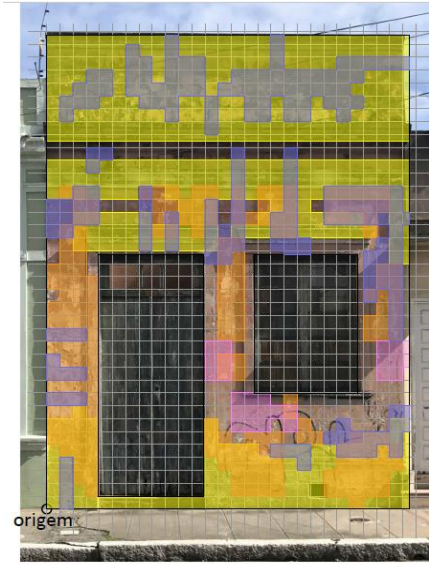

LEGENDA MMD - SANTOS (2018):

EFLORESCÊNCIA

MANCHAS DE UMIDADE, MOFO, BOLOR

DESCOLAMENTO DE REBOCO

DESCOLAMENTO DE PINTURA

FISSURAS, TRINCAS, RACHADURAS

EMPOLAMENTO

Figura 12: Mapa de danos MMD - Fachada ${ }^{\circ} 1021$.

Tabela 1 - Área mapa de danos e Fator de Dano Total (FD) de cada fachada.

\begin{tabular}{|c|c|c|c|c|}
\hline \multicolumn{2}{|c|}{ Rua Gonçalves Chaves, 817} & ÁREA TOTAL $\left(\mathrm{m}^{2}\right)$ & \multicolumn{2}{|c|}{32,06} \\
\hline \multirow{2}{*}{$\begin{array}{l}\text { Manifestações } \\
\text { patológicas }\end{array}$} & ÁREA $\left(\mathrm{m}^{2}\right)$ & ÁREA $\left(\mathrm{m}^{2}\right)$ & \multirow{2}{*}{$\begin{array}{l}\text { Fator de Danos } \\
\text { (FD) }(\%)\end{array}$} & \multirow{2}{*}{$\begin{array}{l}\text { Fator de Danos Total } \\
(\%)\end{array}$} \\
\hline & Mapa de danos & Mapa de danos (MMD) & & \\
\hline Eflorescência & 0,00 & 0,00 & $0,00 \%$ & \multirow{8}{*}{$12,17 \%$} \\
\hline $\begin{array}{c}\text { Manchas de umidade, } \\
\text { mofo e bolor }\end{array}$ & 2,87 & 3,53 & $11,00 \%$ & \\
\hline Descolamento reboco & 0,00 & 0,00 & $0,00 \%$ & \\
\hline Descolamento pintura & 0,03 & 0,20 & $0,62 \%$ & \\
\hline Fissura & - & 0,18 & $0,55 \%$ & \\
\hline Sujidade & 5,70 & - & - & \\
\hline Vegetação & 0,00 & - & - & \\
\hline Empolamento & 0,00 & 0,00 & $0,00 \%$ & \\
\hline \multicolumn{2}{|c|}{ Rua Gonçalves Chaves, 1021} & ÁREA TOTAL $\left(\mathrm{m}^{2}\right)$ & \multicolumn{2}{|c|}{17,42} \\
\hline \multirow{2}{*}{$\begin{array}{l}\text { Manifestações } \\
\text { patológicas }\end{array}$} & ÁREA $\left(\mathrm{m}^{2}\right)$ & ÁREA $\left(\mathrm{m}^{2}\right)$ & \multirow{2}{*}{$\begin{array}{l}\text { Fator de Danos } \\
\text { (FD) }(\%)\end{array}$} & \multirow{2}{*}{$\begin{array}{l}\text { Fator de Danos Total } \\
(\%)\end{array}$} \\
\hline & Mapa de danos & Mapa de danos (MMD) & & \\
\hline Eflorescência & 0,00 & 0,00 & $0,00 \%$ & \multirow{8}{*}{$118,40 \%$} \\
\hline $\begin{array}{c}\text { Manchas de umidade, } \\
\text { mofo e bolor }\end{array}$ & 7,46 & 11,01 & $63,19 \%$ & \\
\hline Descolamento reboco & 0,00 & 0,00 & $0,00 \%$ & \\
\hline Descolamento pintura & 1,97 & 4,70 & $26,95 \%$ & \\
\hline Fissura & - & 4,36 & $25,04 \%$ & \\
\hline Sujidade & 0,15 & - & - & \\
\hline Vegetação & 0,00 & - & - & \\
\hline Empolamento & 0,10 & 0,56 & $3,21 \%$ & \\
\hline
\end{tabular}

No cálculo do fator de dano total das fachadas (FD) (Tabela 1), foi possível observar que o FD da fachada $\mathrm{n}^{\circ} 817$ foi de $12,17 \%$ enquanto o da fachada de $\mathrm{n}^{\circ} 1021$ foi de $118,40 \%$, em ambas as fachadas há predominância das manifestações patológicas de manchas de umidade, mofo e bolor, sendo na fachada ${ }^{\circ} 81711 \%$ do danos totais e $63,19 \%$ na fachada 
n¹021. De acordo com Souza (2016), devido aos estudos abordarem diversas anomalias, o FD Total pode ultrapassar o valor de $100 \%$. Este fato justifica-se por existirem sobreposição de anomalias dentro de uma mesma fachada.

Conforme a Tabela 2 e as Figuras 13 e 14, o Fator de Dano das Regiões (FDR) leva em consideração a área com presença de anomalias em cada região da fachada, considera-se aqui todas as manifestações contidas nesse espaço. Seu resultado apresenta distorção da realidade ao ser influenciado diretamente pelo tamanho da área da região, por isso, deve ser ajustado e proporcionalizado.

Tabela 2 - Fator de Dano das Regiões (FDR) de cada fachada.

\begin{tabular}{|c|c|c|}
\hline \multirow[b]{2}{*}{ Rua Gonçalves Chaves, 817} & & \multirow[b]{2}{*}{32,06} \\
\hline & ÁREA TOTAL $\left(\mathrm{m}^{2}\right)$ & \\
\hline \multirow{2}{*}{ Regiões } & ÁREA $\left(\mathrm{m}^{2}\right)$ & \multirow{2}{*}{$\begin{array}{l}\text { Fator de Dano das Regiões } \\
(\text { FDR })(\%)\end{array}$} \\
\hline & dano/malha/região & \\
\hline 1. Sacadas (SC) & - & - \\
\hline 2. Aberturas $(\mathrm{AB})$ & 0,15 & $0,47 \%$ \\
\hline 3. Cantos e Extremidades (CE) & 1,08 & $3,36 \%$ \\
\hline 4. Transição entre Pavimentos (TP) & - & - \\
\hline 5. Topo (TO) & 0,00 & $0,00 \%$ \\
\hline 6. Paredes Contínuas (PC) & 2,48 & $7,72 \%$ \\
\hline Rua Gonçalves Chaves, 1021 & ÁREA TOTAL $\left(\mathrm{m}^{2}\right)$ & 17,42 \\
\hline \multirow{2}{*}{ Regiões } & ÁREA $\left(\mathrm{m}^{2}\right)$ & \multirow{2}{*}{$\begin{array}{c}\text { Fator de Dano das Regiões } \\
(\text { FDR })(\%)\end{array}$} \\
\hline & dano/malha/região & \\
\hline 1. Sacadas (SC) & - & - \\
\hline 2. Aberturas $(\mathrm{AB})$ & 1,96 & $11,27 \%$ \\
\hline 3. Cantos e Extremidades (CE) & 1,50 & $8,58 \%$ \\
\hline 4. Transição entre Pavimentos (TP) & - & - \\
\hline 5. Topo $(\mathrm{TO})$ & 6,39 & $36,66 \%$ \\
\hline 6. Paredes Contínuas (PC) & 4,52 & $25,95 \%$ \\
\hline
\end{tabular}

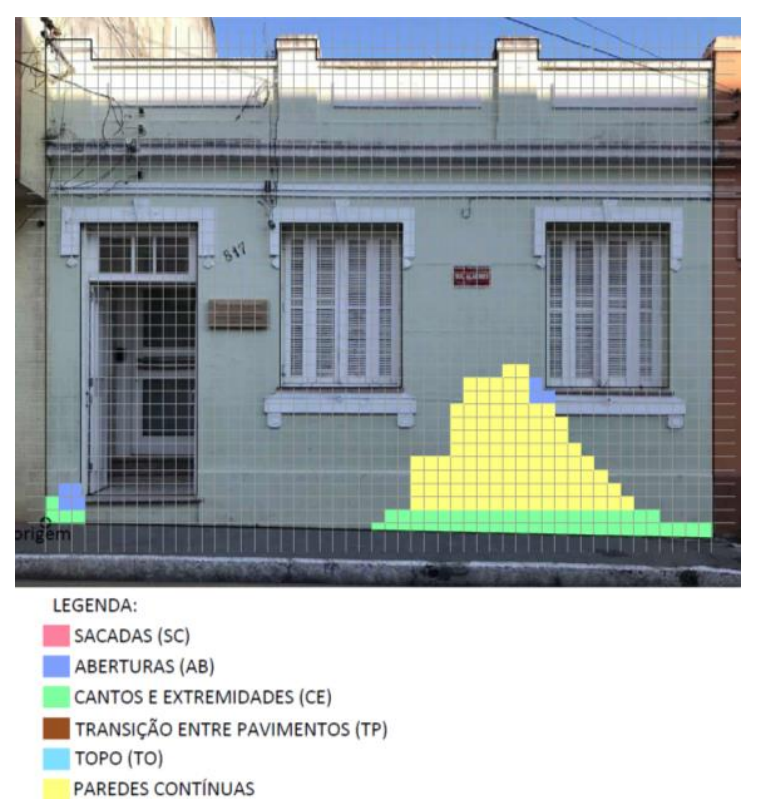

Figura 13: Fator de Dano das Regiões (FDR) - Fachada do imóvel nº 817. 


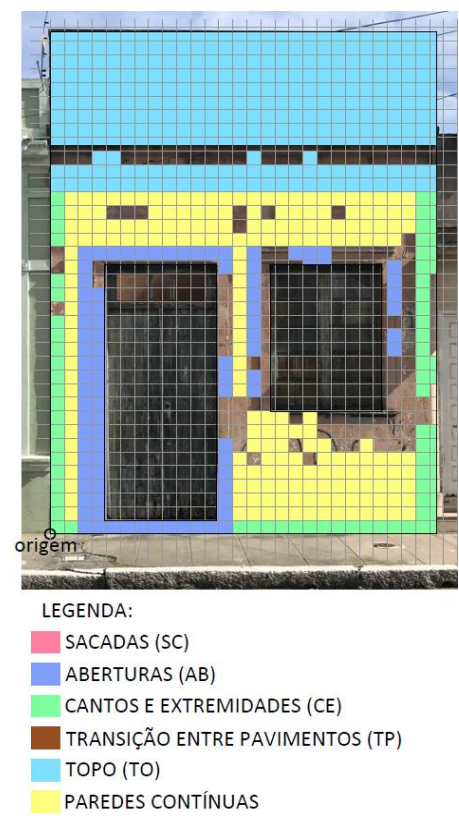

Figura 14: Fator de Dano das Regiões (FDR) - Fachada do imóvel nº 1021.

Para corrigir a desproporcionalidade existente nas áreas de cada região, é calculado o Coeficiente de Correção das Regiões (CCr) de cada região, em vista da classificação das fachadas em regiões poder ocasionar distorção no resultado dos danos. Por fim com o resultado do CCr incidindo sob Fator de Danos das Regiões (FDR), temos a representação mais aproximada da real recorrência dos danos presentes nas regiões da fachada apresentado na Tabela 3 por meio da multiplicação do Fator de Dano das Regiões (FDR) pelo seu respectivo Coeficiente de Correção das Regiões (CCr). Sendo desta maneira apresentados os dados finais para o estudo em questão, no que tange a aplicação do MMD.

Tabela 3 - Coeficiente de Correção das regiões (CCr) e Fator de Danos das regiões corrigido (FDRC) de cada fachada

\begin{tabular}{|c|c|c|c|c|}
\hline \multicolumn{3}{|c|}{ Rua Gonçalves Chaves, 817} & ÁREA TOTAL $\left(\mathrm{m}^{2}\right)$ & 32,06 \\
\hline \multirow[t]{2}{*}{ Regiões } & \multirow{2}{*}{$\begin{array}{l}\text { ÁREA } \\
\left(\mathrm{m}^{2}\right)\end{array}$} & \multirow{2}{*}{$\begin{array}{l}\text { Coeficiente de } \\
\text { Correção das } \\
\text { Regiões (CCr) }\end{array}$} & ÁREA $\left(m^{2}\right)$ & \multirow{2}{*}{$\begin{array}{l}\text { Fator de Danos das } \\
\text { regiões corrigido } \\
\text { (FDRC) }(\%)\end{array}$} \\
\hline & & & dano/malha & \\
\hline 1. Sacadas (SC) & - & - & - & - \\
\hline 2. Aberturas $(\mathrm{AB})$ & 2,87 & 1,00 & 0,15 & $0,47 \%$ \\
\hline 3. Cantos e Extremidades (CE) & 3,02 & 0,95 & 1,08 & $3,18 \%$ \\
\hline $\begin{array}{l}\text { 4. Transição entre Pavimentos } \\
\text { (TP) }\end{array}$ & - & - & - & - \\
\hline 5. Topo $(\mathrm{TO})$ & 10,85 & 0,26 & 0,00 & $0,00 \%$ \\
\hline 6. Paredes Contínuas (PC) & 13,25 & 0,22 & 2,48 & $1,67 \%$ \\
\hline \multicolumn{3}{|c|}{ Rua Gonçalves Chaves, 1021} & ÁREA TOTAL $\left(\mathrm{m}^{2}\right)$ & 17,42 \\
\hline \multirow[t]{2}{*}{ Regiões } & \multirow{2}{*}{$\begin{array}{l}\text { ÁREA } \\
\left(\mathrm{m}^{2}\right)\end{array}$} & \multirow{2}{*}{$\begin{array}{l}\text { Coeficiente de } \\
\text { Correção das } \\
\text { Regiões (CCr) }\end{array}$} & ÁREA $\left(m^{2}\right)$ & \multirow{2}{*}{$\begin{array}{l}\text { Fator de Danos das } \\
\text { regiões corrigido } \\
\text { (FDRC) }(\%)\end{array}$} \\
\hline & & & dano/malha & \\
\hline 1. Sacadas (SC) & - & - & - & - \\
\hline 2. Aberturas $(\mathrm{AB})$ & 3,18 & 0,53 & 1,96 & $5,94 \%$ \\
\hline 3. Cantos e Extremidades (CE) & 1,68 & 1,00 & 1,50 & $8,61 \%$ \\
\hline $\begin{array}{l}\text { 4. Transição entre Pavimentos } \\
\text { (TP) }\end{array}$ & - & - & - & - \\
\hline 5. Topo $(\mathrm{TO})$ & 7,21 & 0,23 & 6,39 & $8,55 \%$ \\
\hline 6. Paredes Contínuas (PC) & 5,33 & 0,32 & 4,52 & $8,18 \%$ \\
\hline
\end{tabular}


Diante do que foi apresentado é possível destacar que a região mais degradada em ambas as edificações são os cantos e extremidades sendo $3,18 \%$ da área representado por essa região encontrasse em degradação na fachada $\mathrm{n}^{\circ} 817$, sendo na fachada de $\mathrm{n}^{\circ} 10218,61 \%$. Além disso, pelo alto FD total da fachada $\mathrm{n}^{\circ} 1021$ de $118,40 \%$ as regiões de topo e paredes contínuas também apresentam alto FDRC, $8,55 \%$ e $8,18 \%$ respectivamente.

\section{CONCLUSÕES}

A metodologia destinada para a avaliação do estado de conservação dos revestimentos de fachada da edificação mostrou-se eficaz. A partir do levantamento realizado é possível destacar as fachadas dos edifícios históricos como elementos que sofrem grande exposição dos agentes destrutivos como as intempéries. Diante do que foi apresentado, foi possível concluir que ambas edificações apresentam fachadas com processo de degradação, muito embora, a fachada n817 apresentar baixo Fator de Dano em vista de possuir uso. É importante mencionar a presença de diversas manifestações patológicas, sendo possível concluir que este nível de degradação tem relação com o desuso e a falta de manutenção da edificação, evidenciando a necessidade de restauração considerando que este quadro tende a avançar aceleradamente.

\section{REFERÊNCIAS}

ALMEIDA, L.M.; BASTOS, M.S. A Experiência da cidade de Pelotas no processo de preservação patrimonial. Revista Centro de Preservação Cultura, v. 1, n. 2, p. 96-118, 2006.

ASSOCIAÇÃO BRASILEIRA DE NORMAS TÉCNIAS. NBR 5674 - Manutenção de edificações - Procedimento. Rio de Janeiro, 1999.

HAUTEQUESTT FILHO, G.C.; ACHIAMÉ, G.G. Diretrizes para representação gráfica de mapa de danos. In: CONFERÊNCIA SOBRE PATOLOGIA E REABILITAÇÃO DE EDIFÍCIOS, 6., 2018, Rio de Janeiro, 2018. Anais http://www.nppg.org.br/patorreb/files/artigos/80626.pdf > Acesso em: 13 dez. 2019.

IOSHIMOTO, E. Incidências de manifestações patológicas em edificações habitacionais. In: Tecnologia de edificações. Coletânea de trabalhos da Divisão de Edificações do IPT - Instituto de Pesquisas Tecnológicas do Estado de São Paulo. São Paulo: Pini, IPT, 1988. p. 545-548.

IPHAN, Instituto do Patrimônio Histórico e Artístico Nacional. Conjuntos urbanos tombados (cidades históricas). Disponível em: http://portal.iphan.gov.br/pagina/detalhes/123 > Acesso em: 13 dez. 2019.

IPHAN, Instituto do Patrimônio Histórico e Artístico Nacional. Normatização de cidades históricas - orientações para a elaboração de diretrizes e normas de preservação para áreas urbanas tombadas. Disponível em: http://portal.iphan.gov.br/uploads/publicacao/normatizacao_areas_tombadas_cidades_historicas_2011.pdf > Acesso em: 13 dez. 2019.

PELOTAS. Lei no . 4.490, 27 de fevereiro de 2003. Dispõe sobre os bens integrantes do inventário do patrimônio cultural de Pelotas. Pelotas, 2003. https://leismunicipais.com.br/a/rs/p/pelotas/decreto/2003/449/4490/decreto-n-44902003-dispoe-sobre-os-bens-integrantes-do-inventario-do-patrimonio-cultural-de-pelotas > Acesso em: 13 dez. 2019.

PELOTAS. Lei no . 4.568, 07 de julho de 2000. Declara área da cidade como Zonas de Preservação do Patrimônio Cultural de Pelotas - ZPPCS - lista seus bens integrantes e dá outras providências. Pelotas, 2000. https://leismunicipais.com.br/a/rs/p/pelotas/lei-ordinaria/2000/456/4568/lei-ordinaria-n-4568-2000-declara-area-dacidade-como-zonas-de-preservacao-do-patrimonio-cultural-de-pelotas-zppcs-lista-seus-bens-integrantes-e-da-outrasprovidencias-2000-07-07 > Acesso em: 13 dez. 2019.

PELOTAS. Manual do usuário de imóveis inventariados - Parte 1. Prefeitura Municipal de Pelotas, Secretaria de Cultura. Pelotas: Nova Prova, 2008. 50 p.

PEREIRA, L.M. Avaliação das patologias e da biodeterioração na biblioteca central da UFSM. 2012.126 f. Dissertação (Mestrado em Engenharia Civil) - Programa em Pós-graduação em Engenharia Civil e Ambiental, Universidade Federal de Santa Maria, Santa Maria, 2012. 
RIBEIRO, F.M.T. Políticas públicas referentes ao patrimônio cultural edificado na cidade de Pelotas, RS: o caso da isenção do IPTU. 2013. 163 f. Dissertação (Mestrado em Memória Social e Patrimônio Cultural) - Programa de Pós-Graduação em Memória Social e Patrimônio Cultural, Universidade Federal de Pelotas, Pelotas, 2013.

RODRIGHIERO, J. C; OLIVEIRA, A.L.C. A Valoração do significado cultural: o exemplo de Pelotas - RS. In: ENCONTRO DA ASSOCIAÇÃO NACIONAL DE PESQUISA E PÓS-GRADUAÇÃO EM ARQUITETURA E URBANISMO - ARQUITETURA E URBANISMO NO BRASIL ATUAL CRISES, IMPASSES E DESAFIOS, 4., 2018, Salvador. Anais... Salvador: ENANPARQ, 2018. p. 5300-5317.

RODRIGUES, A.O. Metodologia para identificação de manifestações patológicas baseada em estudo de caso na cidade de Pelotas/RS, aplicada ao desenvolvimento de banco de dados. 2016. 119 f. Dissertação (Mestrado em Arquitetura e Urbanismo) - Programa de Pós-Graduação em Arquitetura e Urbanismo, Universidade Federal de Pelotas, Pelotas, 2016.

SANTOS, D. G. Estudo da vida útil e degradação de fachadas em argamassa a partir da inspeção de edifícios. 2018. 122 f. Dissertação (Mestrado em Estruturas e Construção Civil) - Departamento de Engenharia Civil e Ambiental, Universidade de Brasília, Brasília, 2018.

SCHLEE, A.R. Pela Memória de Pelotas. Como sempre! In: COLÓQUIO SOBRE HISTÓRIA E HISTORIOGRAFIA DA ARQUITETURA BRASILEIRA, I., 2008, Brasília. Anais https://sites.google.com/site/coloquiohh08/Home > Acesso em: 13 dez. 2019.

SILVA, V.M.B. Manifestações patológicas em fachadas de empreendimentos do programa de arrendamento residencial na cidade de Pelotas/RS: Residenciais Solar das Palmeiras e Paraíso. 2016. 148 f. Dissertação (Mestrado em Arquitetura e Urbanismo) - Programa de Pós-Graduação em Arquitetura e Urbanismo, Faculdade de Arquitetura e Urbanismo, Universidade Federal de Pelotas, Pelotas, 2016.

SOUZA, J.S. Evolução da Degradação de Fachadas - Efeito dos Agentes de Degradação e dos Elementos Constituintes. 2016. 114 f. Dissertação (Mestrado em Estruturas e Construção Civil) - Departamento de Engenharia Civil e Ambiental, Universidade de Brasília, Brasília, 2016.

TINOCO, J.E.L. Mapa de danos recomendações básicas. serie 2, volume 43. Olinda: centro de estudos avançados da conservação integrada - textos para discussão - gestão de restauro, 2009. 23 p.

TIRELLO, R.A.; CORREA, R. Sistema Normativo para mapas de danos de edifícios históricos aplicados à Lidgerwood Manufacting Company de Campinas. In: COLÓQUIO LATINOAMERICANO SOBRE RECUPERAÇÃO E PRESERVAÇÃO DO PATRIMÔNIO INDUSTRIAL, $\quad$ VI., $\quad 2012, \quad$ São $\quad$ Paulo. Anais http://portal.iphan.gov.br/uploads/ckfinder/arquivos/VI_coloquio_t1_sistema_normativo_mapa.pdf > Acesso em: 13 dez. 2019.

TERRA, R.C. Levantamento de manifestações patológicas de fachadas das edificações da cidade de Pelotas. 2001. 133 f. Dissertação (Mestrado em Engenharia Civil) - Programa de Pós-graduação em Engenharia Civil, Universidade Federal do Rio Grande do Sul, Porto Alegre, 2001.

VIEIRA, A.A. Influência dos detalhes arquitetônicos no estado de conservação das fachadas de edificações do patrimônio cultural do centro histórico de Porto Alegre: estudo de caso. 2005. 163 f. Dissertação (Mestrado Profissional em Engenharia) - Curso de Mestrado Profissionalizante em Engenharia, Universidade Federal do Rio Grande do Sul, Porto Alegre, 2005.

ZANONI, V.A.G. Influência dos agentes climáticos no comportamento higrotérmico de fachadas em Brasília. 2015. 313 f. Tese (Doutorado em Arquitetura e Urbanismo) - Programa de Pesquisa e Pós-Graduação em Arquitetura e Urbanismo, Universidade de Brasília, Brasília, 2015. 